\title{
An interleaved DC charging solar system for electric vehicle
}

\author{
Ahmad Aiman Mohd Faudzi', Siti Fauziah Toha ${ }^{2}$, Rabiatuladawiah Abu Hanifah ${ }^{3}$, Nurul Fadzlin \\ Hasbullah $^{4}$, Nor Azam Kamisan ${ }^{5}$ \\ 1,2,3 Department of Mechatronics Engineering, Kulliyyah of Engineering, International Islamic University Malaysia, \\ Malaysia \\ ${ }^{4}$ Department of Electrical and Computer Engineering, Kulliyyah of Engineering, International Islamic University \\ Malaysia, \\ ${ }^{5}$ Pumar Solar Power Sdn. Bhd., Lot G-03, Plaza Seremban Utara, Jalan Tun Dr. Ismail, 70200 Seremban, Negeri \\ Sembilan, Malaysia
}

\begin{tabular}{|c|c|}
\hline Article Info & ABSTRACT \\
\hline Article history: & \multirow{10}{*}{$\begin{array}{l}\text { This paper investigates the performance of conventional boost converter, } \\
\text { 2-phase interleaved boost converter and 3-phase interleaved boost converter for } \\
\text { renewable energy applications especially for solar-powered energy. The } \\
\text { advantages of using coupled inductors in interleaved boost converters include } \\
\text { increased system efficiency, reduced core size, and also reduced overall current } \\
\text { and voltage ripples which increases the lifetime of renewable energy resources. } \\
\text { In this paper, the uses of boost converters have been focused explicitly on the } \\
\text { interleaved DC-DC charging from a solar-powered battery into electric vehicle } \\
\text { (EV) battery storage. Hence, this paper aims to investigate a suitable charging } \\
\text { process mechanism from a photovoltaic (PV) battery storage system into EV } \\
\text { powered battery system. Using the application of a boost converter with } \\
\text { reduced ripple current and ripple voltage decreases switching losses and } \\
\text { increases conversion efficiency. The simulation is carried out by using } \\
\text { Simulink/MATLAB to evaluate the performance of each boost converter. The } \\
\text { results successfully demonstrate the ability of the proposed charging system } \\
\text { with an energy efficiency of } 90 \% \text {. }\end{array}$} \\
\hline Received Dec 30, 2020 & \\
\hline Revised Sep 7, 2021 & \\
\hline Accepted Sep 14, 2021 & \\
\hline Keywords: & \\
\hline Boost converter & \\
\hline Electric vehicle & \\
\hline Interleaved technique & \\
\hline MATLAB & \\
\hline Solar energy & \\
\hline
\end{tabular}

This is an open access article under the CC BY-SA license.

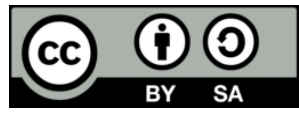

\section{Corresponding Author:}

Siti Fauziah Toha

Department of Mechatronics Engineering

Kulliyyah of Engineering

International Islamic University Malaysia, Malaysia

Email: tsfauziah@iium.edu.my

\section{INTRODUCTION}

The transportation sector is recognized as the main contributor to the worrisome effect of the green house gases $(\mathrm{GHG})$ and thus, the electric vehicle (EV) technology is regarded as one of the prominent solutions towards the reduction of this problem [1], [2]. In EV technology, the vehicle relies on the battery instead of fuel as the energy supply for its system operation. Due to the limited and constrain power available in the battery for the EV, various studies have been conducted to prolong the battery life and maximizing the EV potential for long-run operation [3], [4]. The research on the EV system is not only limited to the components and control strategy in the EV system itself, the charging strategy is also another means towards the improvement of the EV for sustainability in the transportation sector [5], [6].

Nowadays, being able to charge the EV can mean the difference between hours of care-free use or scrambling to find the nearest power outlet. The issue of electrical burden has been raised during the peak demand duration and requires methods to overcome the drawbacks [7]-[9]. The impact of charging the EV 
transportation networks influenced directly the generation, transmission and distribution of power grids [10], [11]. An OFF-grid or the standalone charging system emerged as the best option for electrification as it eliminates the need for the connection to the charging utility such as the requirements for the transmission and distribution on the power grid [12]. Moreover, it is very well suitable to meet the power need especially in remote areas as it relies on renewable energy resources [13], [14]. Renewable energy comes from many commonly known sources such as solar power, wind, water and geothermal.

The idea of a solar charging system seizes researchers' attention to provide a solution for power crisis issues while suggesting a clean, economical, and sustainable power source for an electric vehicle. However, many issues have been raised when the proposed application of high power charging system solely depending on only solar energy system [15]. Specifically, for solar-powered energy, a combination of photovoltaic (PV) with the power grid system and PV-Standalone Charger are an excellent method that has been proposed [16]-[18]. Both of them require a suitable converter to make it more efficient since the conversion efficiency of the PV array is very small compared to the battery storage capacity [19]-[21]. A conventional boost converter is one such converter that can be optimized for these applications.

Hence, this paper aims to investigate a suitable charging process mechanism from the PV battery storage system into EV powered battery system. Using the application of a boost converter with reduced ripple current and ripple voltage decreases switching losses and increases conversion efficiency. By implementing a boost converter, all goals can be achieved except for line and load regulations since it only can be improved by using the higher quality capacitors so that it can hold up the voltage better on the circuit board [22]. By using the interleaving method, also called multi-phasing, which requires a parallel combination of multiple sets of switches, diodes and inductors connected to a single capacitor, it can effectively reduce the size of the filter components while exhibits lower output current and voltage ripples [23], [24]. Theoretically, interleaving methods can cover the losses due to the phase shift of 180 degrees ripple cancellation takes place [25].

The remainder of this paper is organized as shown in. The background of the study of this paper is introduced in section 1. While the details of the operation for each converter namely; conventional boost converter, 2-phase interleaved boost converter (IBC) and 3-phase interleaved boost converter are described in section 2 and the simulation of the PV characteristics is described in section 3 . The selection of the suitable charging mechanism is elaborated in section 4. Finally, the paper is concluded with findings from the analysis in section 5 .

\section{METHODOLOGY}

In this paper, three types of topologies for the DC-DC converter charging system are studied and investigated namely; the conventional boost converter, 2-phase interleaved boost converter and 3-phase interleaved boost converter. The higher output voltage can be produced when using the large inductor that is connected in series with the power supply. When the switch is on, the inductor gets charged by the supply, and when the switch is off, both the supply and the indicator will give supply to the load and act as the transformers from DC to DC. Even though it has many advantages, its application is limited due to the ripple current and voltage. Ripples are wasted power and have many undesirable effects in a DC circuit such as it heats the components, affecting the digital circuits to operate improperly and also contributes to noise and distortion. The ripple can be reduced by an electronic filter and some can be eliminated by using a voltage regulator [26].

\subsection{Duty ratio, $D$}

Duty cycle, D of the proposed charger can be expressed as shown in (1).

$$
D=1-\frac{V_{\text {in }} \times \eta}{V_{\text {out }}}
$$

Where $V_{\text {out }}$ is the output voltage, $V_{\text {in }}$ is the input voltage, and $\eta$ is the efficiency of the converter.

\subsection{Inductor, $\mathbf{L}$}

The inductor, L can be expressed as shown in (2).

$$
L=\frac{V_{\text {in }} *\left(V_{\text {out }}-V_{\text {in }}\right)}{\Delta I_{L} * f_{S^{*}} V_{\text {out }}}
$$

where $f_{S}$ and $\Delta I_{L}$ are the minimum switching frequency of the converter and estimated inductor current ripple respectively. For the $\Delta I_{L}$, a good estimation for the inductor ripple current is $20 \%$ to $40 \%$ of the output 
current. Theoretically, a smaller ripple current reduces the magnetic hysteresis losses in the inductor, as well as output voltage ripple. The formula can be found out as shown in (3).

$$
\Delta I_{L}=(0.2 \text { to } 0.4) * I_{\text {out }(\max )} * \frac{V_{\text {out }}}{V_{\text {in }}}
$$

Where $I_{\text {out (max) }}$ is the maximum output current desired in the application. After calculating the value of inductance $\mathrm{L}$, we can verify the value of inductor ripple current $\Delta I_{L}$ using (4).

$$
\Delta I_{L}=\frac{V_{\text {in }(\min ) * D}}{f_{S} * L}
$$

\subsection{Capacitor, $\mathrm{C}$}

In the proposed charger, capacitor $\mathrm{C}$ resonated with inductor $\mathrm{L}$ to smoothen out switch voltage at turn-off transition. Thus, the suitable energy to be stored in $\mathrm{C}$ can be determined as 5 .

$$
C_{\text {out }(\min )}=\frac{I_{\text {out }(\max )^{* D}}}{f_{s} * \Delta V_{\text {out }}}
$$

where $C_{\text {out(min) }}$ and $I_{\text {out(max) }}$ are the minimum output capacitance needed and maximum output current of the desired application respectively. While $\Delta V_{\text {out }}$ is the desired output voltage ripple.

\subsection{Resistance, $\mathbf{R}$}

Interleaving also can be known as multi-phase is a developed technique to overcome the conventional boost converter disadvantages. It is a useful technique to reduce the size of filter components by setting the components into a parallel combination of a set of two switches, diodes, and inductor that is connected to a single capacitor and load. The load or resistance, R, value can be calculated using (6).

$$
R=\frac{V_{\text {out }}}{I_{\text {out }}}
$$

\section{PV CHARACTERISTIC}

For the solar characteristic, there are many types of PV modeling methods available, and one of them is the single diode model of the PV Module. By using SIMSCAPE and Simulink software, the simulation is conducted to determine the relationship between the variation of irradiance and temperature level with the output power produced. The characteristic of the PV panel applied in this study is listed in Table 1. Several irradiance levels are tested for the test which include $600 \mathrm{~W} / \mathrm{m}^{2}, 700 \mathrm{~W} / \mathrm{m}^{2}, 800 \mathrm{~W} / \mathrm{m}^{2}$, $900 \mathrm{~W} / \mathrm{m}^{2}$, and $1000 \mathrm{~W} / \mathrm{m}^{2}$ with a constant temperature of $25^{\circ} \mathrm{C}$. Based on the plotted graph on Figure 1 (a), the reduction of irradiance will affect the output power of PV panel and changing its maximum power point (MPP) position. The power axis range is from $1.957 \mathrm{~V}$ to $3.396 \mathrm{~V}$ for irradiance variation from $600 \mathrm{~W} / \mathrm{m}^{2}$ to $1000 \mathrm{~W} / \mathrm{m}^{2}$

Since irradiance with $1000 \mathrm{~W} / \mathrm{m}^{2}$ will provide the highest MPP value, the model is tested with a different value of temperature including $10^{\circ} \mathrm{C}, 20^{\circ} \mathrm{C}, 30^{\circ} \mathrm{C}, 40^{\circ} \mathrm{C}$, and $50^{\circ} \mathrm{C}$ with a constant irradiance of $1000 \mathrm{~W} / \mathrm{m}^{2}$. Figure 1 (b) portrays the P-V characteristics on a different level of temperature. Similar to Irradiance variation, temperature changes also will affect the output power of the PV panel while changing its MPP position. The Power axis range from $3.339 \mathrm{~W}$ to $3.431 \mathrm{~W}$ for temperature range $10^{\circ} \mathrm{C}$ to $50^{\circ} \mathrm{C}$. It is known that the conversion efficiency of the PV array is very small compared to the battery capacity [27], [28]. Thus, to increase efficiency, high-energy processors are required. Transformers is not suitable for this project because transformers can only step up AC-AC but this scope of study only covers a stand-alone offgrid system. Hence, this project mainly adopts a DC-DC converter to increase the voltage to the desired amount using the boost converter.

$\underline{\text { Table 1. Specification of PV panel }}$

\begin{tabular}{lc}
\hline \multicolumn{1}{c}{ Parameter } & Value \\
\hline Open Circuit Voltage $\left(V_{\{O C\}}\right)$ & 48 \\
Short Circuit Current $\left(I_{\{S C\}}\right)$ & 9.2 \\
Quality Factor & 1.5 \\
Series Cell & 1 \\
Energy Gap & 1.11 \\
\hline
\end{tabular}




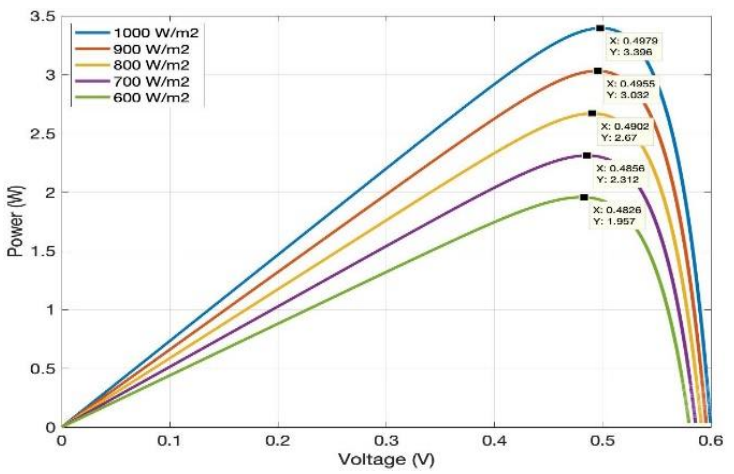

(a)

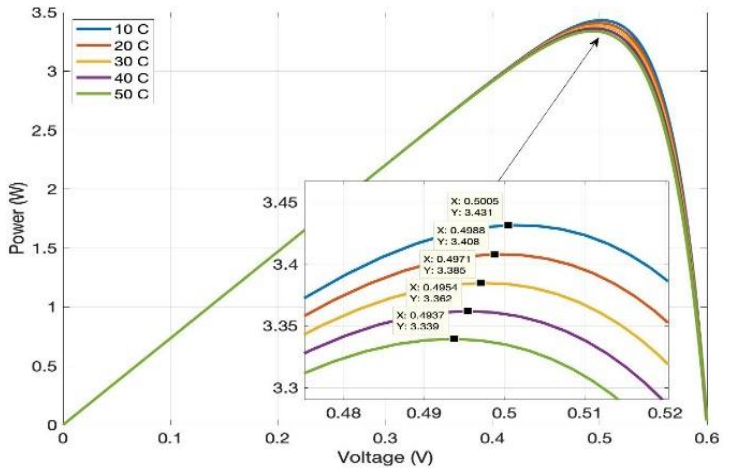

(b)

Figure 1. Input waveforms of PV curve depending on; (a) the irradiance level and (b) the temperature level

\section{RESULT AND DISCUSSION}

The analysis from the simulation is explained in terms of the efficiency of the converters, the reduction of values of ripple and the transition time from the transient state into the steady state in the system design that has been developed earlier. For the simulation of the conventional boost converter, the inputs to the system are demonstrated by Figure 2 (a) and (b). As mentioned earlier, the current that goes into the inductor is similar to the input current are shown in Figure 2 (a). They can be obtained as 10.39 A, and by using the same waveform, the input current ripple is obtained as $2.35 \mathrm{~A}$. And Figure 2 (b) shows the gating pattern of MOSFET.

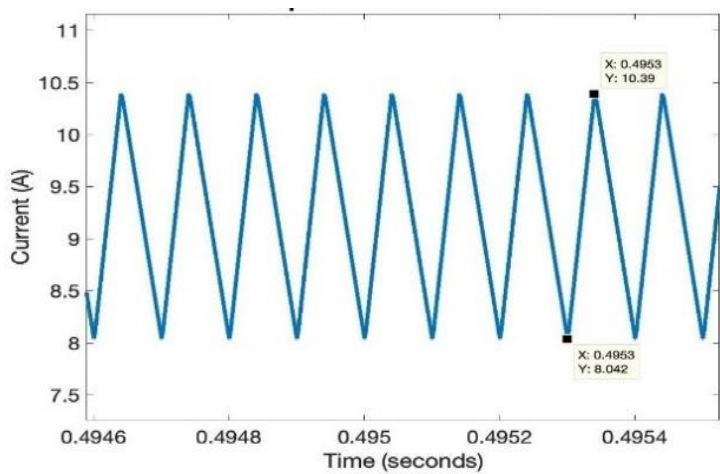

(a)

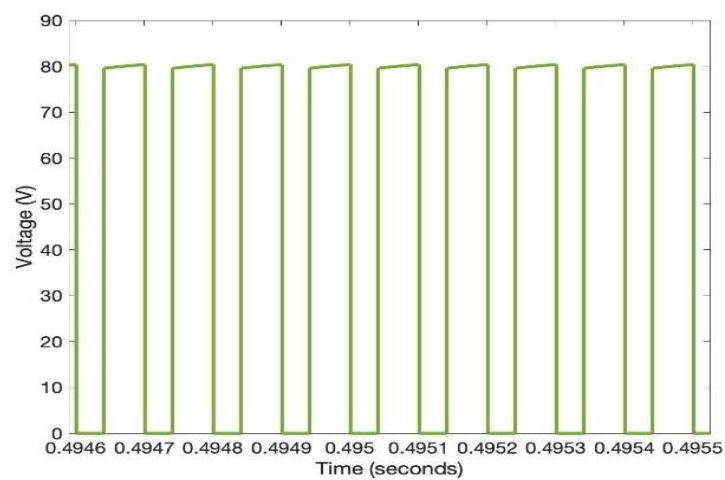

(b)

Figure 2. Input waveforms of conventional boost converter; (a) current and (b) gating pattern of MOSFET

For the 2-phase interleaved boost converter, Figure 3 (a) shows the input current waveform, inductor L1 and inductor L2 current waveforms with the values of $9.936 \mathrm{~A}$ and $3.469 \mathrm{~A}$ respectively. Using the same waveform, the input current ripple is accumulated as $0.76 \mathrm{~A}$, and both inductor current ripples are $2.35 \mathrm{~A}$, similar to the conventional boost converter. The gating pattern of MOSFET M1 and MOSFET M2 of 2-Phase interleaved boost converter is shown in Figure 3 (b). In the simulation of 3-phase interleaved boost converter, the input current, inductor currents (L1, L2, and L3) are shown in Figure 4 (a) and are detected at 9.019 A and 4.315 A respectively. Meanwhile, the input current ripple is obtained at $0.52 \mathrm{~A}$ and all inductor current ripples are at the value of $2.35 \mathrm{~A}$, the same value detected in conventional boost converter and 2-phase interleaved boost converter. The switching patterns of three MOSFETs M1, M2, and M3 in the 3-phase interleaved boost converter can be demonstrated in Figure 4 (b). The phase shift is recorded at 120 degrees $(360 / \mathrm{n}$ where $\mathrm{n}$ is 3$)$. 


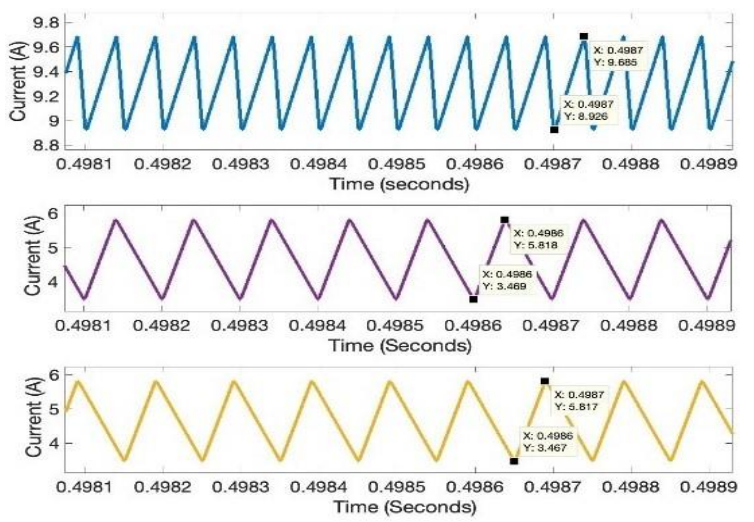

(a)

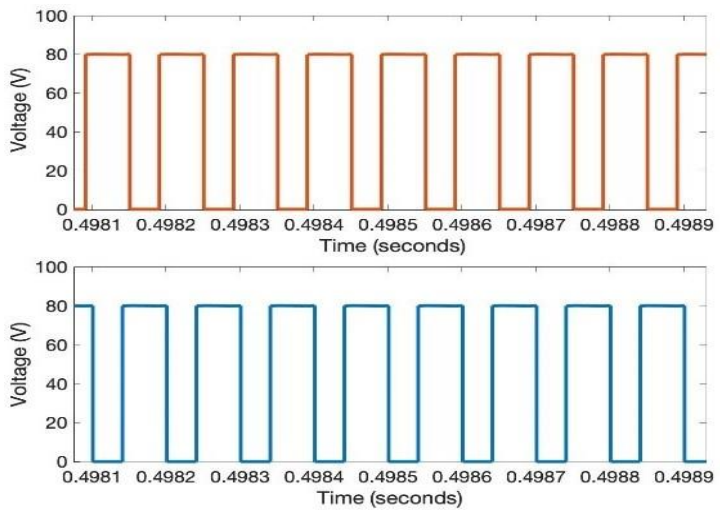

(b)

Figure 3. Waveform of the 2-phase interleaved boost converter (a) input current and (b) gating pattern of MOSFET
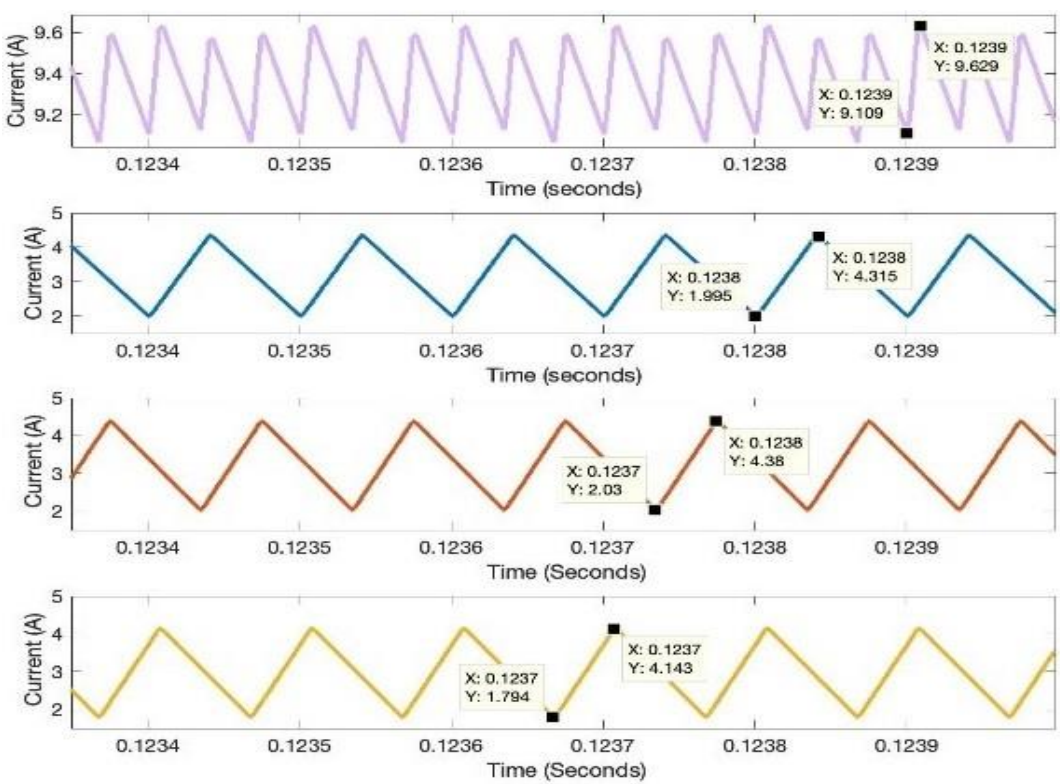

(a)
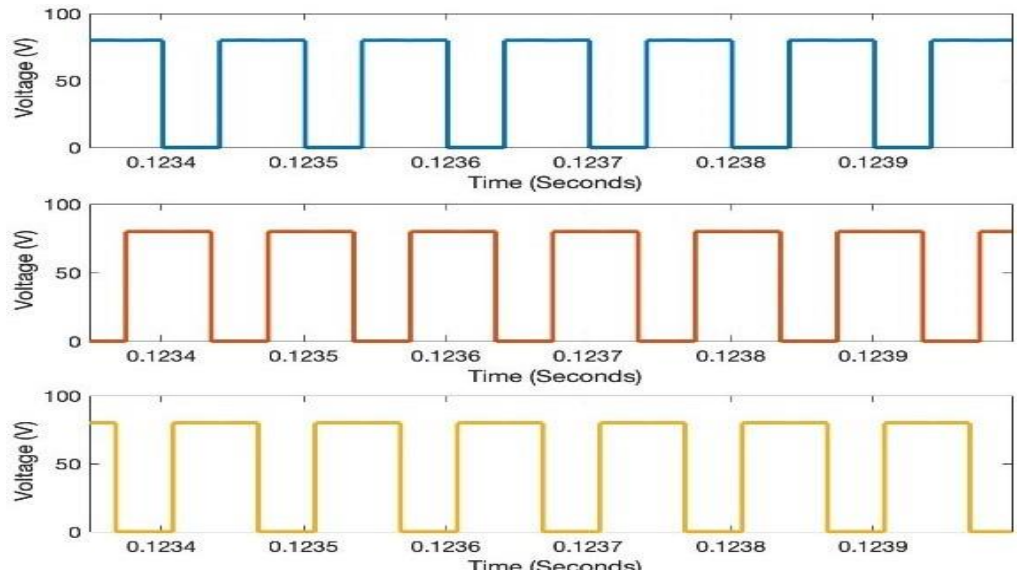

(b)

Figure 4. Waveform of the 3-phase interleaved boost converter (a) input current and (b) gating pattern of MOSFET 


\subsection{Comparative analysis}

Based on Figure 5 (a) and (b), the conventional boost converter produced the output current and output voltage of 5.523 A and $79.54 \mathrm{~V}$ respectively. The output current ripple can be calculated from the same figure and is calculated at the value of $0.79 \mathrm{~V}$. Thus, the efficiency of the conventional boost converter is only up to $88.09 \%$. However, the transient response of the system for the conventional boost converter shows that a longer setting time is needed for this type of converter as shown in Figure 6. Moreover, the conventional boost converter simulation results do not produce the expected result, to run efficiently in stepping up the voltage level. So, to overcome the drawbacks, the idea of having an interleaved boost converter is applied.

When the system is applied with the 2-phase interleaved boost converter, the output current is detected at 5.503 A and the output voltage is at $79.25 \mathrm{~V}$. Thus, the efficiency of a 2-phase interleaved boost converter is $91.44 \%$ which is better than a conventional boost converter. The output current ripple for the 2-phase interleavedboost converter can be observed in Figure 5(a) and Figure 5(b) at 0.046 A, with the output voltage ripple is $0.14 \mathrm{~V}$. In terms of the transient response in Figure 6, the 2-phase interleaved boost converter exhibits a much better and faster response in comparison to the conventional boost converter but with slightly slower than the 3-phase interleaved boost converter.

When the system is applied with the 3-phase interleaved boost converter, the output current is detected at 5.501 A while output voltage is at $79.21 \mathrm{~V}$ as demonstrated in Figure 5. Hence, the efficiency becomes $99.66 \%$ which makes the 3-phase interleaved boost converter has the highest efficiency among all tested converters in this study. The output current ripple is calculated at $0.004 \mathrm{~A}$ and the output voltage ripple is also shown in Figure 5 with a value of $0.060 \mathrm{~V}$. It can be inferred from the Figure 5, that when the interleaved methods are applied, the ripple will be reduced significantly.

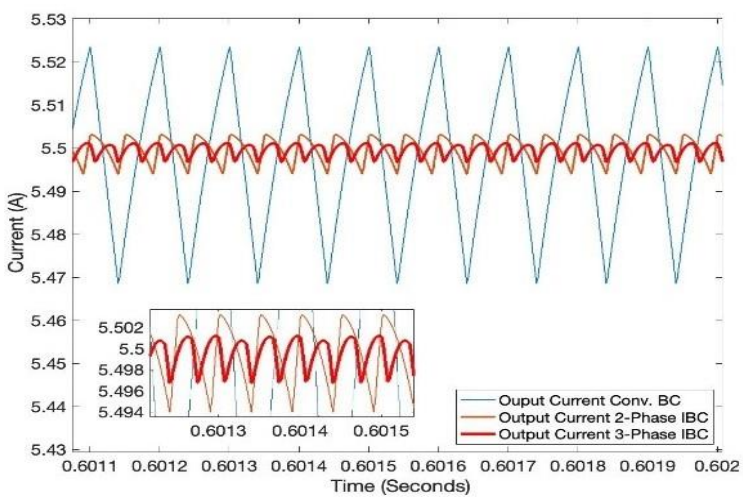

(a)

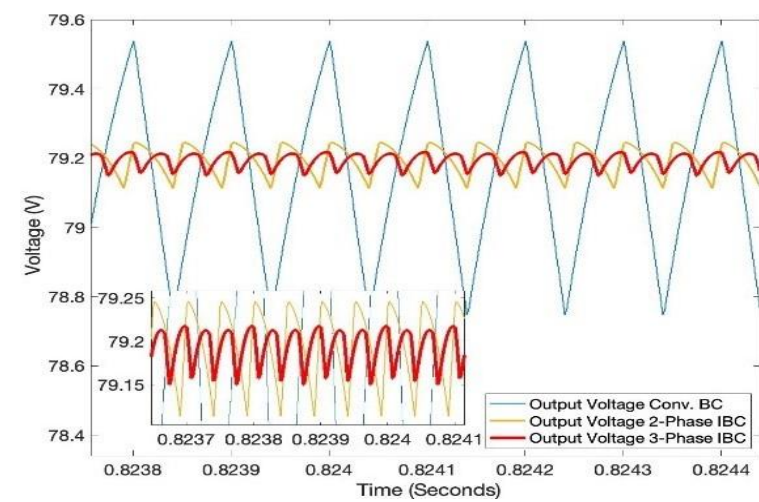

(b)

Figure 5. Output waveforms of the conventional boost converter, (a) current, (b) voltage

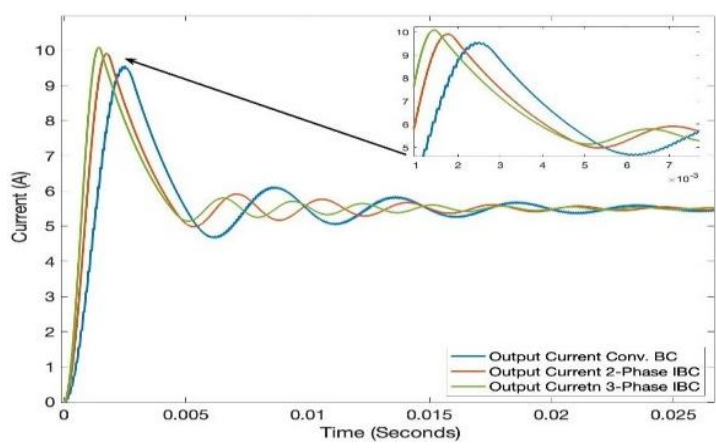

(a)

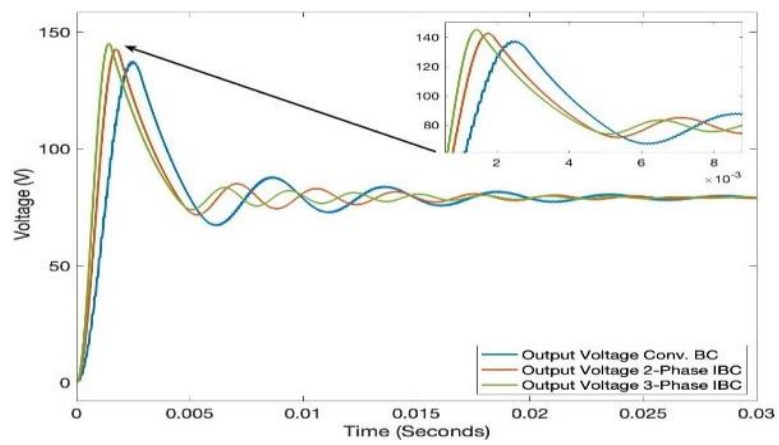

(b)

Figure 6. Transient-steady state of output waveforms, (a) current, (b) voltage

Furthermore, Figure 6 (a) shows the time taken for the current to change from a transient state into a steady state. Between those three boost converters, 3-phase interleaved boost converter shows the fastest 
transition compared to the other two. Similarly, Figure 6 (b) shows the time taken for the voltage to change from a transient state into a steady-state, 3-Phase interleaved boost converter also leads to the transition process. Table 2 summarises the complete comparisons between conventional boost converter, 2-phase interleaved boost converter, and 3-phase interleaved boost converter.

Table 2. Comparison of boost converters

\begin{tabular}{lccc}
\hline \multicolumn{1}{c}{ Parameters } & $\begin{array}{c}\text { Conventional } \\
\text { Boost Converter }\end{array}$ & $\begin{array}{c}\text { 2-Phase Interleaved } \\
\text { Boost Converter }\end{array}$ & $\begin{array}{c}\text { 3-Phase Interleaved } \\
\text { Boost Converter }\end{array}$ \\
\hline Input Voltage & $48 \mathrm{~V}$ & $48 \mathrm{~V}$ & $48 \mathrm{~V}$ \\
Input Current & $10.39 \mathrm{~A}$ & $9.936 \mathrm{~A}$ & $9.109 \mathrm{~A}$ \\
Input Power & $498.72 \mathrm{~W}$ & $476.928 \mathrm{~W}$ & $437.232 \mathrm{~W}$ \\
Output Voltage & $79.54 \mathrm{~V}$ & $79.25 \mathrm{~V}$ & $79.21 \mathrm{~V}$ \\
Output Current & $5.523 \mathrm{~A}$ & $5.503 \mathrm{~A}$ & $5.501 \mathrm{~A}$ \\
Output Power & $439.3 \mathrm{~W}$ & $436.113 \mathrm{~W}$ & $435.73 \mathrm{~W}$ \\
Efficiency & $88.09 \%$ & $91.44 \%$ & $99.66 \%$ \\
Duty Ratio & 0.4 & 0.4 & 0.4 \\
Switching Frequency & $10 \mathrm{kHz}$ & $10 \mathrm{kHz}$ & $10 \mathrm{kHz}$ \\
Inductor Current Ripple & $2.35 \mathrm{~A}$ & $2.35 \mathrm{~A}$ & $2.35 \mathrm{~A}$ \\
Output Current Ripple & $0.054 \mathrm{~A}$ & $0.046 \mathrm{~A}$ & $0.004 \mathrm{~A}$ \\
Output Voltage Ripple & $0.79 \mathrm{~V}$ & $0.14 \mathrm{~V}$ & $0.060 \mathrm{~V}$ \\
\hline
\end{tabular}

\section{CONCLUSION}

This paper aims to investigate a suitable charging process mechanism from a Photovoltaic (PV) battery storage system into EV powered battery system. Using the application of a boost converter with reduced ripple current and ripple voltage decreases switching losses and increases conversion efficiency. The effect of a coupled inductors on both the inductor current ripple, the output current ripple, and the output voltage ripple is studied in great detail. The major contributions of the paper are summarized as; To investigate suitable charging process mechanism from PV battery storage system into EV powered battery system; To design and develop an interleaved boost converter with a reduction of ripple current and voltage to decrease switching losses and increase conversion efficiency; To evaluate the performance of the interleaved boost converter as the DC-DC Charging System between PV battery storage system and EV powered system. From the analysis, it is shown that the output current ripple is reduced from $0.054 \mathrm{~A}$ in conventional boost converter into $0.046 \mathrm{~A}$ in 2-phase interleaved boost converter and $0.004 \mathrm{~A}$ in 3-phase interleaved boost converter. The output voltage ripple also is reduced from $0.79 \mathrm{~V}$ in conventional boost converter to $0.14 \mathrm{~V}$ in 2-phase interleaved boost converter and $0.06 \mathrm{~V}$ in 3-phase interleaved boost converter. Thus, it justified that the leakage inductance could be prevented by increasing the switching patterns to minimize the output Current and voltage ripples. Furthermore, the 3-phase interleaved boost converter also has the fastest transition from a transient state into a steady-state compared to 2-phase interleaved boost converter and conventional boost converter. Additionally, the simulation results, validate that 3-phase interleaved boost converter has higher efficiency than a 2-phase interleaved boost converter. Therefore, a 3phase interleaved boost converter is proven to be a suitable candidate for DC-DC charging system for renewable energy resources specifically in the electric vehicle application.

\section{ACKNOWLEDGEMENTS}

The author would like to thank financial support from the Ministry of Higher Education Malaysia, Prototype Research Grant Scheme, PRGS19-014-0058” High Resolution 4H-Silicon Carbide Electron Radiation Detector".

\section{REFERENCES}

[1] R. A. Hanifah, S. F. Toha, S. Ahmad and M. K. Hassan, "Swarm-Intelligence Tuned Current Reduction for PowerAssisted Steering Control in Electric Vehicles," in IEEE Transactions on Industrial Electronics, vol. 65, no. 9, pp. 7202-7210, Sept. 2018, doi: 10.1109/TIE.2017.2784344.

[2] C. E. Thomas, "Greenhouse gases by sector," in Stopping Climate Change: The Case for Hydrogen and Coal. New York, NY, USA: Springer, 2017, pp. 9-11.

[3] R. Abu Hanifah, S. F. Toha, N. H. H. Mohamad Hanif and N. A. Kamisan, "Electric Motorcycle Modeling for Speed Tracking and Range Travelled Estimation," in IEEE Access, vol. 7, pp. 26821-26829, 2019, doi: 10.1109/ACCESS.2019.2900443. 
[4] C. M. Martinez, X. Hu, D. Cao, E. Velenis, B. Gao and M. Wellers, "Energy Management in Plug-in Hybrid Electric Vehicles: Recent Progress and a Connected Vehicles Perspective," in IEEE Transactions on Vehicular Technology, vol. 66, no. 6, pp. 4534-4549, June 2017, doi: 10.1109/TVT.2016.2582721.

[5] Y. Xue, J. You, X. Liang, and H.-C. Liu, "Adopting Strategic Niche Management to Evaluate EV Demonstration Projects in China," Sustainability, vol. 8, no. 2, p. 142, 2016, doi: 10.3390/su8020142.

[6] Z. Fotouhi, M. R. Hashemi, H. Narimani and I. S. Bayram, "A General Model for EV Drivers' Charging Behavior," in IEEE Transactions on Vehicular Technology, vol. 68, no. 8, pp. 7368-7382, Aug. 2019, doi: 10.1109/TVT.2019.2923260.

[7] P. Shrivastava, M. S. Alam, and M. S. J. Asghar, "Design and techno-economic analysis of plug-in electric vehicleintegrated solar PV charging system for India," IET Smart Grid, vol. 2, no. 2, pp. 224-232, 2019, doi: 10.1049/ietstg.2020.0035.

[8] N. M. L. Tan, A. K. Ramasamy, V. K. Ramachandaramurthy, M. Marsadek, M. R. Othman, and I. Ariffin, "Utilityscale photovoltaic generators: a review on trends, grid code requirements and challenges," Indonesian Journal of Electrical Engineering and Computer Science, vol. 18, no. 2, pp. 573-585, 2020, doi: 10.11591/ijeecs.v18.i2.pp573-585.

[9] S. Gorai, D. Sattianadan, V. Shanmugasundaram, S. Vidyasagar, G. R. P. Kumar, and M. Sudhakaran, "Investigation of voltage regulation in grid connected PV system," Indonesian Journal of Electrical Engineering and Computer Science, vol. 19, no. 3, pp. 1131-1139, 2020, doi: 10.11591/ijeecs.v19.i3.pp1131-1139.

[10] E. Xydas, C. Marmaras, L. M. Cipcigan, N. Jenkins, S. Carroll, and M. Barker, "A data-driven approach for characterising the charging demand of electric vehicles: A UK case study,” Applied Energy, vol. 162, pp. 763-771, 2016, doi: 10.1016/j.apenergy.2015.10.151.

[11] D. Tang and P. Wang, "Probabilistic Modeling of Nodal Charging Demand Based on Spatial-Temporal Dynamics of Moving Electric Vehicles," in IEEE Transactions on Smart Grid, vol. 7, no. 2, pp. 627-636, March 2016, doi: 10.1109/TSG.2015.2437415.

[12] A. Hassoune, M. Khafallah, A. Mesbahi, and T. Bouragba, "Optimization Techniques for DC Bus Voltage Balancing in a PV Grid System Based EVs Charging Station," Recent Advances in Electrical and Information Technologies for Sustainable Development, 2019, pp. 123-131, doi: 10.1007/978-3-030-05276-8_14.

[13] J. Philip et al., "Control and implementation of a standalone solar photo-voltaic hybrid system," 2015 IEEE Industry Applications Society Annual Meeting, 2015, pp. 1-8, doi: 10.1109/IAS.2015.7356814.

[14] M. Reyasudin Basir Khan, J. Pasupuleti, J. Al-Fattah, M. Tahmasebi, M. Reyasudin, and B. Khan, "Optimal GridConnected PV System for a Campus Microgrid," Indonesian Journal of Electrical Engineering and Computer Science, vol. 12, no. 3, pp. 899-906, 2018, doi: 10.11591/ijeecs.v12.i3.pp899-906.

[15] A. Z. Adnan, M. E. Yusoff, and H. Hashim, "Analysis on the Impact of Renewable Energy to Power System Fault Level,” Indonesian Journal of Electrical Engineering and Computer Science, vol. 11, no. 2, pp. 652-657, 2018, doi: 10.11591/ijeecs.v11.i2.pp652-657.

[16] M. J. E. Alam, K. M. Muttaqi and D. Sutanto, "Effective Utilization of Available PEV Battery Capacity for Mitigation of Solar PV Impact and Grid Support With Integrated V2G Functionality," in IEEE Transactions on Smart Grid, vol. 7, no. 3, pp. 1562-1571, May 2016, doi: 10.1109/TSG.2015.2487514.

[17] M. Al-Maghalseh, "Generation unit sizing, economic analysis of grid connected and standalone PV power plant," International Journal of Energy Applications and Technologies, vol. 6, no. 1, pp. 1-7, 2019, doi: 10.31593/ijeat.444091.

[18] Z. A. Arfeen, A. B. Khairuddin, A. Munir, M. K. Azam, M. Faisal, and M. S. B. Arif, "En route of electric vehicles with the vehicle to grid technique in distribution networks: Status and technological review," Energy Storage, vol. 2, no. 2, 2020, doi: 10.1002/est2.115.

[19] N. S., D. Debnath and C. Chakraborty, "Synthesis of Three-Port Converter from existing dc-dc converters for PV based dc stand-alone system," 2020 IEEE International Conference on Power Electronics, Smart Grid and Renewable Energy (PESGRE2020), 2020, pp. 1-6, doi: 10.1109/PESGRE45664.2020.9070443.

[20] K. Sayed, M. G. Gronfula, and H. A. Ziedan, "Novel soft-switching integrated boost DC-DC converter for PV power system," Energies, vol. 13, no. 3, p. 749, 2020, doi: 10.3390/en13030749.

[21] M. Aref, I. Ahmed, and V. Oboskalov, "Digital control strategy for SPWM MPPT of PV system with three-phase NPC three-level converter," Indonesian Journal of Electrical Engineering and Computer Science, vol. 19, no. 2, pp. 572-585, 2020, doi: 10.11591/ijeecs.v19.i2.pp572-585.

[22] S. Jain, S. Dhara and V. Agarwal, "A Voltage-Zone Based Power Management Scheme With Seamless Power Transfer Between PV-Battery for OFF-Grid Stand-Alone System," in IEEE Transactions on Industry Applications, vol. 57, no. 1, pp. 754-763, Jan.-Feb. 2021, doi: 10.1109/TIA.2020.3031265.

[23] X. Hu, P. Ma, J. Wang and G. Tan, "A Hybrid Cascaded DC-DC Boost Converter With Ripple Reduction and Large Conversion Ratio," in IEEE Journal of Emerging and Selected Topics in Power Electronics, vol. 8, no. 1, pp. 761-770, March 2020, doi: 10.1109/JESTPE.2019.2895673.

[24] T. V. Muni, D. Priyanka, and S. V. N. L. Lalitha, "Fast Acting MPPT Algorithm for Soft Switching Interleaved Boost Converter for Solar Photovoltaic System Power management system," Journal of Advanced Research in Dynamical and Control Systems, vol. 10, no. 9, 2018.

[25] D. SKoushik, "Modeling and Analysis of Two Phase Interleaved Boost DC to DC Converter for Renewable Energy Applications," International Journal of AdvancedResearch in Science, Engineering and Technology, vol. 5, 2018.

[26] H. -S. Lee and J. -J. Yun, "High-Efficiency Bidirectional Buck-Boost Converter for Photovoltaic and Energy Storage Systems in a Smart Grid," in IEEE Transactions on Power Electronics, vol. 34, no. 5, pp. 4316-4328, May 2019, doi: 10.1109/TPEL.2018.2860059. 
[27] S. Pathy, R. Sridhar, N. Hari, S. S. Dash and C. Subramani, "A modified module integrated - Interleaved boost converter for standalone photovoltaic (PV) application," 2016 IEEE International Conference on Renewable Energy Research and Applications (ICRERA), 2016, pp. 989-994, doi: 10.1109/ICRERA.2016.7884483.

[28] E. Hendawi, "A high performance grid connected PV system based on HERIC transformerless inverter," Indonesian Journal of Electrical Engineering and Computer Science, vol. 20, no. 2, pp. 602-612, 2020, doi: 10.11591/ijeecs.v20.i2.pp602-612.

\section{BIOGRAPHIES OF AUTHORS}
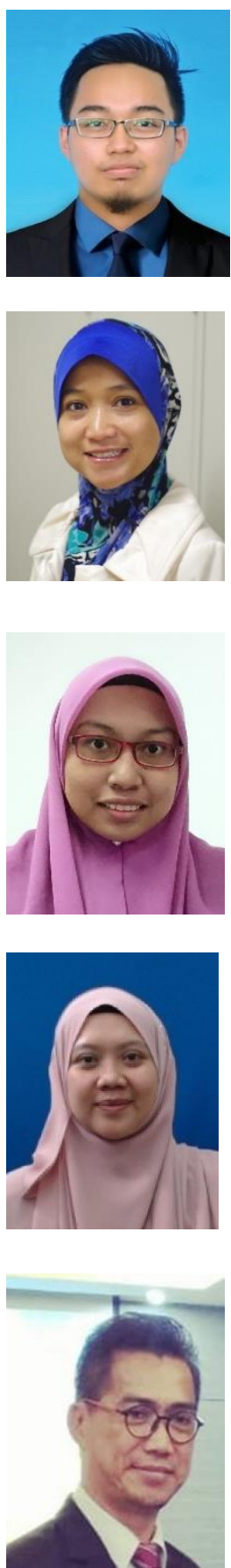

Ahmad Aiman Mohd Faudzi is a graduate at International Islamic University Malaysia with bachelor's degree in Mechatronics Engineering in 2019. His research is in fields of electronics and digital systems. He is affiliated with IEEE as a student member and was awarded Best Final Year Project in 2019 by IEEE Intrumentation $\backslash \&$ Measurement Society Malaysia Chapter. Besides, he was also involved in NGOs, student societies, and instructed robotics program in schools. Currently, he is a system engineer at Utility Automation Sdn. Bhd., a power system company based in Selangor, Malaysia. Further info on his homepage: https://www.linkedin.com/in/aimanfaudzi-004375158/

Siti Fauziah Toha is currently an Associate Professor at the Department of Mechatronics Engineering, International Islamic University Malaysia (IIUM). She received B. Eng (Hons) in Electrical and Electronics Engineering from University Technology Petronas and later received MSc from Universiti Sains Malaysia in electrical engineering. She was then completed her PhD in Automatic Control and Systems Engineering from The University of Sheffield in 2010. Dr Toha is a senior member of IEEE and also a Professional Engineer in Malaysia as well as a Chartered Engineer with Engineering Council, The Institution of Engineering and Technology, United Kingdom. She is also an active member of Young Scientist Network, Academy of Sciences Malaysia (YSN-ASM).

Rabiatuladawiah Abu Hanifah was born in Kuala Lumpur, Malaysia. She received the B. Eng (Hons) in Mechatronics Engineering and MSc degrees in Mechatronics Engineering from International Islamic University Malaysia in 2011 and 2014 respectively. In 2020, she successfully graduated and completed her PhD in International Islamic University Malaysia researching on the enhancement of complex controller optimization for the electric vehicle. Her research interests are in system controller parameter and performance optimization using various computational intelligence methods. Dr. Rabiatul is a student member of IEEE and also a registered graduate engineer of Board of Engineers Malaysia. In ITEES, IEEE Transactions journals and other scientific publications, she has served as invited reviewer.

Nurul Fadzlin Hasbullah is currently a Professor at the Department of Electrical and Computer Engineering, Faculty of Engineering. She graduated with a First-Class Honours from Cardiff University, Wales, with a Bachelor of Engineering in 2001. Later, she worked as an Integrated Chip Design Engineer in Malaysia Microelectronics Solution, Cyberjaya for a year before joining academia, teaching at the University Tenaga Nasional (Bangi, Malaysia) as a tutor. In 2003, she moved to International Islamic University Malaysia as an Assistant Lecturer. She obtained her Ph.D from the University of Sheffield, UK in 2010 researching on the electrical and optical characteristics of quantum dot laser structures. Her research interests continue in the areas of semiconductor device characterization, optical detectors and radiation hard devices.

Nor Azam Kamisan is currently designated as the CEO of PUMAR Solar Power Sdn, Bhd. He receives his B.Eng in Material Hydrodynamic from Akita University of Japan, Japan in 1999. Later, he pursues his MSc. in Business Studies /Administration/ Management from the University of Technology MARA, Malaysia in 2012. With his 14 years of experience in business management, he had hold position in numerous prominent corporations in Malaysia including LANDMARC International Properties Sdn Bhd, AMK IKKYU Corporation Sdn Bhd, HONDA MALAYSIA Sdn Bhd and Perodua Manufacturing Sdn Bhd. 